\title{
A Direct Comparison of Three Clinically Relevant Treatments in a Rat Model of Cervical Spinal Cord Injury
}

\author{
Hillary Hosier,, David Peterson,, Orest Tsymbalyuk, Kaspar Keledjian,, Bradley R. Smith, \\ Svetlana Ivanova, Volodymyr Gerzanich,' Phillip G. Popovich,, and J. Marc Simard ${ }^{3}$
}

\begin{abstract}
Recent preclinical studies have identified three treatments that are especially promising for reducing acute lesion expansion following traumatic spinal cord injury (SCI): riluzole, systemic hypothermia, and glibenclamide. Each has demonstrated efficacy in multiple studies with independent replication, but there is no way to compare them in terms of efficacy or safety, since different models were used, different laboratories were involved, and different outcomes were evaluated. Here, using a model of lower cervical hemicord contusion, we compared safety and efficacy for the three treatments, administered beginning $4 \mathrm{~h}$ after trauma. Treatment-associated mortality was 30\% (3/10), 30\% (3/10), $12.5 \%$ (1/8), and 0\% (0/7) in the control, riluzole, hypothermia, and glibenclamide groups, respectively. For survivors, all three treatments showed overall favorable efficacy, compared with controls. On open-field locomotor scores (modified Basso, Beattie, and Bresnahan scores), hypothermia- and glibenclamidetreated animals were largely indistinguishable throughout the study, whereas riluzole-treated rats underperformed for the first two weeks; during the last four weeks, scores for the three treatments were similar, and significantly different from controls. On beam balance, hypothermia and glibenclamide treatments showed significant advantages over riluzole. After trauma, rats in the glibenclamide group rapidly regained a normal pattern of weight gain that differed markedly and significantly from that in all other groups. Lesion volumes at six weeks were: $4.8 \pm 0.7,3.5 \pm 0.4,3.1 \pm 0.3$ and $2.5 \pm 0.3 \mathrm{~mm}^{3}$ in the control, riluzole, hypothermia, and glibenclamide groups, respectively; measurements of spared spinal cord tissue confirmed these results. Overall, in terms of safety and efficacy, systemic hypothermia and glibenclamide were superior to riluzole.
\end{abstract}

Key words: glibenclamide; hypothermia; rat; riluzole; spinal cord injury; sulfonylurea receptor 1 (Sur1)

\section{Introduction}

$S^{\text {nim }}$ PINAL CORD INJURy (SCI) IS A DEBILITATING neurological injury that typically requires lifelong therapy and rehabilitative care. Worldwide, the incidence of SCI ranges from 10 to 83 per million people per year, with half of these patients suffering a complete lesion and one-third becoming tetraplegic. ${ }^{1,2}$ In the United States, up to 1.275 million people live with SCI and 12,000 20,000 new cases are added yearly. ${ }^{3,4}$ Long-term disability resulting from SCI translates not only into enormous personal and financial losses for the affected individual but also into substantial burdens to the economy and the health care system. ${ }^{5}$

Traumatic SCI is marked by acute lesion expansion, (i.e., volumetric expansion that occurs principally during the first several hours after trauma). Volumetric expansion describes the progres- sive conversion of normal tissue into abnormal tissue that is caused by severe advancing microvascular dysfunction, and which gives rise to both edematous progression and hemorrhagic progression of the lesion. ${ }^{6,7}$ Edematous progression may, in principal, be reversible, but hemorrhagic progression, also known as progressive hemorrhagic necrosis (PHN), leads to irreversible tissue destruction. ${ }^{8}$ Acute lesion expansion has been documented using serial magnetic resonance imaging in experimental $\mathrm{SCI},{ }^{9,10}$ as well as in humans with SCI. ${ }^{11}$ PHN has been causally linked to the upregulation of Sur1-Trpm 4 channels in microvascular endothelial cells, leading to microvascular dysfunction and capillary fragmentation. ${ }^{12-14}$ There is a critical need to develop safe and effective treatments to prevent acute lesion expansion after traumatic SCI in order to optimize recovery-both spontaneous recovery as well as that which is anticipated from cell-based therapies.

\footnotetext{
${ }^{1}$ Department of Neurosurgery, ${ }^{3}$ Departments of Neurosurgery, Pathology and Physiology, University of Maryland, Baltimore, Maryland.

${ }^{2}$ Center for Brain and Spinal Cord Repair, the Ohio State University, Columbus, Ohio.
}

(c) Hillary Hosier, David Peterson, Orest Tsymbalyuk, Kaspar Keledjian, Bradley R. Smith, Svetlana Ivanova, Volodymyr Gerzanich, Phillip G. Popovich, J. Marc Simard 2015; Published by Mary Ann Liebert, Inc. This Open Access article is distributed under the terms of the Creative Commons Attribution Noncommercial License (http://creativecommons.org/licenses/by-nc/4.0/) which permits any noncommercial use, distribution, and reproduction in any medium, provided the original author(s) and the source are credited. 
Recent preclinical studies have identified three treatments that are especially promising for reducing acute lesion expansion in SCI: riluzole, ${ }^{15-19}$ systemic hypothermia, ${ }^{20-23}$ and glibenclamide. ${ }^{8,9,12,24-26}$ All have been reported to reduce lesion size and improve neurological function in various cervical and thoracic rat models of SCI. Although each of these treatments has repeatedly demonstrated efficacy in multiple studies with independent replication, there is no way to compare them in terms of efficacy, since different models were used, different laboratories were involved, and different outcomes were evaluated. ${ }^{27}$ Similarly, there is no way to compare them in terms of safety, since each may have its own treatment-associated complications or untoward side effects, especially in the context of injury. Critically important questions remain as to which of these three treatments, if any, should be advanced to clinical trials. Here, we report on a comparison of riluzole, systemic hypothermia, and glibenclamide administered beginning $4 \mathrm{~h}$ after trauma performed in a single laboratory using the same SCI model, with treatment outcomes evaluated by investigators blinded to treatment group during all but the first week after trauma.

\section{Methods}

\section{Ethics statement}

All methods and data are reported with consideration for the guidelines provided by Animals in Research: Reporting in Vivo Experiments (ARRIVE) and Minimum Information About a Spinal Cord Injury Experiment (MIASCI). ${ }^{28,29}$ Further, we certify that all applicable institutional and governmental regulations concerning the ethical use of animals were followed during the course of this research. Animal experiments were performed under a protocol approved by the Institutional Animal Care and Use Committee of the University of Maryland, Baltimore and in accordance with the relevant guidelines and regulations as stipulated in the United States National Institutes of Health Guide for the Care and Use of Laboratory Animals. All efforts were made to minimize the number of animals used and their suffering.

\section{Subjects}

These experiments were conducted on new groups of animals distinct from those previously reported from this laboratory. In all, 35 female Long-Evans rats (ages 10-12 weeks; 200-225 g; Harlan, Frederick, MD) underwent SCI (see below for injury details) and were assigned to one of four groups: no treatment after injury (10 rats); riluzole (10 rats); hypothermia (eight rats); or glibenclamide (seven rats). All treatments were started $4 \mathrm{~h}$ after injury (see treatment details below). Survivors were maintained for six weeks after injury, during which they underwent various evaluations for well-being and for neurological function, and after which they were euthanized to measure lesion volumes.

\section{Sample size calculation}

We based our sample size calculation on a previous study ${ }^{30}$ that used the same model of SCI and compared riluzole and glibenclamide, except that in the previous study the impact force was greater ( $30 \mathrm{vs} .25 \mathrm{~mm}$ drop of a $10 \mathrm{~g}$ weight), and the doses of the two drugs were lower. In that study, mean lesion volumes were 2.2 and $1.2 \mathrm{~mm}^{3}$ for riluzole versus glibenclamide (standard deviation, $0.6 \mathrm{~mm}^{3}$ ). These values yield an effect size (Cohen's d) of 1.7. Sample size calculation for a two-sample comparison $(\alpha=0.05$; two-tailed), an effect size of 1.7 , and a power of $80 \%$, indicated a minimum sample size of seven per group. In order to maintain a balanced design for the analysis of long-term outcomes, the number of animals in each group was increased, commensurate with early mortality.

\section{Rat model of SCl}

A unilateral impact to the cervical spinal cord at C7 was calibrated to produce ipsilateral but not contralateral primary hemorrhage. ${ }^{12,25}$ Rats were anesthetized (ketamine, $60 \mathrm{mg} / \mathrm{kg}$ plus xylazine, $7.5 \mathrm{mg} / \mathrm{kg}$, intraperitoneally [IP]) and the head was mounted in a stereotaxic apparatus (Stoelting, Wood Dale, IL). Using aseptic technique and magnification (Zeiss operating microscope with co-axial lighting; Thornwood, NY), the spine was exposed dorsally from C3 to T3 via a $3 \mathrm{~cm}$ midline incision and sub-pereosteal dissection of the paraspinous muscles. The ear bars were removed and the animal was repositioned so that it was supported from the spinous process of T2 (Spinal Adaptor; Stoelting) and the snout. At C7, the spinous process, part of the right lamina, the entire left lamina and the dorsal half of the left pedicle were removed using a 1.9-mm diamond burr (RS-6280C-6; Roboz Surgical Instrument Co., Inc., Gaithersburg, MD) and a high-speed drill, with care taken to avoid mechanical and thermal injury to the underlying dura and spinal cord. The dura was exposed by sharply removing the interlaminar ligaments rostral and caudal to the lamina of $\mathrm{C} 7$ and any remaining ligamentum flavum. The guide tube containing the impactor $(1.55 \mathrm{~mm}$ tip diameter, $57 \mathrm{~mm}$ length, $1.01 \mathrm{~g}$ ) was angled $5^{\circ}$ medially. Using the manipulator arm of the stereotaxic apparatus, the impactor was positioned on the dura mater near the left C8 nerve root. As previously, ${ }^{12,25}$ the caudal edge of the impactor was placed in line with the caudal edge of the $\mathrm{C} 8$ nerve root at the axilla, and the medial edge of the impactor was placed $0.3 \mathrm{~mm}$ medial to the dorsolateral sulcus. The impactor was activated by releasing a $10 \mathrm{~g}$ weight from a height of $25 \mathrm{~mm}$ inside the guide tube. The impact caused an immediate, forceful flexion of the trunk and $70-90^{\circ}$ flexion of the ipsilateral knee, which had been extended before impact, and resulted in a hemorrhagic contusion evident on the surface of the cord involving the ipsilateral but not the contralateral sulcus, as observed under the microscope through the translucent dura.

After injury, the surgical site was flushed with $1 \mathrm{~mL}$ of normal saline (NS), the musculature was replaced over the spine and the skin incision was stapled. Rats in the hypothermia treatment group had an epidural thermoprobe (Flexible Implantable Probe IT-23; Braintree Scientific Inc., Braintree, MA) placed on the dura and loosely sutured to the musculature to secure it in place. All rats were given $10 \mathrm{~mL}$ of glucose-free NS subcutaneously. Rats in the three non-hypothermia groups were nursed on a heating pad (DC temperature controller with feedback; FHC Inc., Bowdoin, ME) to maintain rectal temperature $\sim 37^{\circ} \mathrm{C}$ until they emerged from anesthesia (1-2h). After returning to their cages, a purified high calorie supplement (DietGel Boost; Clear $\mathrm{H}_{2} \mathrm{O}$, Portland, $\mathrm{ME}$ ) and water were placed near the rat to be easily accessible. Bladder function was assessed two to three times daily by observing for urination and by palpating the bladder. Manual expression of the bladder was performed using Credé's maneuver, as needed, until the rats regained reflex voiding.

\section{Controls}

Because comparison groups included two drugs solubilized using different vehicles, and a non-drug group, we elected to have the controls not receive any vehicle or other manipulation.

\section{Riluzole treatment}

Riluzole treatment was based on Wu colleagues, ${ }^{18,19}$ who reported that rats with SCI receiving a dose of $8 \mathrm{mg} / \mathrm{kg}$ IP twice daily had $30 \%$ (3/10 rats) survival, those administered $6 \mathrm{mg} / \mathrm{kg}$ IP twice daily had $92.3 \%(24 / 26)$ survival, and those administered $4 \mathrm{mg} / \mathrm{kg}$ IP twice daily had $100 \%$ survival. Here, we used an intermediate dose of $5 \mathrm{mg} / \mathrm{kg}$ IP twice daily, which was twice the dose we studied previously. ${ }^{30}$ Riluzole was prepared as described, ${ }^{16}$ wherein it was initially dissolved in 45\% (2-hydroypropyl)- $\beta$ cyclodextrin $(2 \mathrm{HP} \beta \mathrm{CD}$ ) with $0.2 \mathrm{~N} \mathrm{HCl}$, then diluted to a final concentration of $5 \mathrm{mg} / \mathrm{mL} ; 1 \mathrm{~N} \mathrm{NaOH}$ was added to adjust to $\mathrm{pH}$ 
7.4. Beginning $4 \mathrm{~h}$ after trauma, the final solution was delivered in phosphate-buffered saline at a dose of $5 \mathrm{mg} / \mathrm{kg}$ IP twice daily for 7 $\mathrm{d}$, adjusted for the rat's actual daily body weight.

\section{Systemic hypothermia treatment}

Temperatures were recorded using both a rectal probe and the epidural probe implanted at surgery. Within 5 min of trauma, the rats were placed on a warming pad and the epidural temperature was maintained at $37 \pm 1^{\circ} \mathrm{C}$ for $4 \mathrm{~h}$. Subsequently, moderate hypothermia (epidural temperature, $33.0 \pm 0.3^{\circ} \mathrm{C}$ ) was induced for $4 \mathrm{~h}$ as described previously. ${ }^{21}$ Rats were transferred to the cooling system, comprised of a water blanket and pump (HTP WD-020 and HTP-1500, Adroit; Medical Systems Corp., Loudon, TN) with the pump reservoir filled with ice water. The rats were covered with a thermal blanket to stabilize their temperature. During this time, they were anesthetized with low-dose isoflurane $(0.75 \%)$ via face mask, to prevent them from shivering or moving and dislodging the temperature probe. They reached the target epidural temperature for hypothermia within $30 \mathrm{~min}$ of starting cooling. Blood oxygen saturation and pulse rate (MouseOx, Starr, Life Sciences Corp, Holliston, MA), as well as respiratory rate, were monitored continuously and recorded every $30 \mathrm{~min}$. After $4 \mathrm{~h}$, the animals were gradually rewarmed at $1{ }^{\circ} \mathrm{C} / \mathrm{h}$ until they were normothermic. After completing the hypothermia treatment, the epidural probes were removed by gentle traction, and the rats were returned to their cages, where food and water were easily accessible.

\section{Glibenclamide treatment}

Glibenclamide treatment consisted of administering a loading dose $(10 \mu \mathrm{g} / \mathrm{kg}, \mathrm{IP}), 4 \mathrm{~h}$ after trauma, plus implanting a mini-osmotic pump for continuous one-week long subcutaneous delivery beginning $4 \mathrm{~h}$ after trauma of $400 \mathrm{ng} / \mathrm{h}$, which was twice the infusion dose that we studied previously. ${ }^{12,25,30}$ Drug formulation and methods of administration have been described in detail. ${ }^{31}$ A stock solution of glibenclamide was prepared by placing $25 \mathrm{mg}$ glibenclamide (\#G2539; meets ISP testing; Sigma, St Louis, MO) into $10 \mathrm{~mL}$ dimethyl sulfoxide. The solution to be loaded into the mini-osmotic pumps (Azlet 2001, $1 \mu \mathrm{L} / \mathrm{h}$; Azlet Corp., Cupertino, CA) was made by taking $2.1 \mathrm{~mL}$ unbuffered NS, adding $4 \mu \mathrm{L}$ of $10 \mathrm{~N} \mathrm{NaOH}$ (undiluted Fixanal; Riedel-deHaën, Seelze, Germany), then adding $400 \mu \mathrm{L}$ stock solution, in that order, to prevent precipitation of drug. The solution to be used for the loading dose was made by adding $4 \mu \mathrm{L}$ of stock solution to $1 \mathrm{~mL} \mathrm{NS}$. After filling the mini-osmotic pumps, they were primed overnight in $\mathrm{NS}$ at $37^{\circ} \mathrm{C}$ with the outlet of the pump connected to a length of PE60 tubing that extended above the level of the priming solution, to prevent $\mathrm{H}+$ ions from entering the pump chamber. Prior to implanting, the pump outlet was fitted with an empty catheter (PE60 tubing), $4 \mu \mathrm{L}$ in volume, that resulted in a 4-h delay in the start of drug infusion. ${ }^{30}$ Loaded and primed miniosmotic pumps were implanted subcutaneously after completing surgery to induce SCI. The pumps delivered $400 \mathrm{ng} / \mathrm{h}$ of glibenclamide for $7 \mathrm{~d}$. The loading dose $(10 \mu \mathrm{g} / \mathrm{kg} \mathrm{IP})$ was administered $4 \mathrm{~h}$ after injury, with the volume of the loading dose in microliters equal to the weight of the rat in grams. After completing the glibenclamide treatment on Day 7, the rats were briefly anesthetized with isoflurane and the mini-osmotic pump was removed to conceal group identity.

\section{Data collection and blinding of investigators}

In accordance with good laboratory practice, different investigators performed surgery for SCI (OT) versus evaluation of outcomes $(\mathrm{HH}$, $\mathrm{DP}, \mathrm{KK}, \mathrm{BRS}, \mathrm{SI})$ and, when possible, outcome evaluations were performed by investigators who were blinded to treatment group. Outcome measures were evaluated in two phases. Phase 1 consisted of the first $7 \mathrm{~d}$ after trauma, during which group identity could not be concealed, because early mortality had to be compensated by adding new animals to the appropriate groups, and because required manipulations or external signs of group identity (twice daily IP injections [riluzole] vs. an implanted mini-osmotic pump [glibenclamide] vs. nothing [controls and hypothermia]) prevented concealment.

During Phase 1, we assessed mortality daily; also, on Days 1, 3, and 7 , we assessed autonomic function (heart rate, rectal temperature, and ipsilateral ptosis), arousal scores (lethargy), motor scores, bladder function, and serum glucose. Also during Phase 1, on Days 1, 3, and 7, we measured modified (unilateral) Basso, Beattie, and Bresnahan (mBBB) scores, performance on the inclined plane, beam balance, and body mass. On Day 8, after external signs of group identity had been removed, de-identified rats were marked with a coded ear tag (National Band and Tag Co., Newport KY) and randomly assigned to cages by a scientist (VG) not involved in outcome evaluations. During Phase 2, de-identified rats were evaluated weekly by blinded investigators ( $\mathrm{HH}, \mathrm{DP}, \mathrm{KK}$, OT) for $\mathrm{mBBB}$ scores, performance on the inclined plane, beam balance, and body mass. Performance on the accelerating rotarod was tested only once, ${ }^{32}$ during Week 6 . After completing the functional evaluations of Week 6 , rats were euthanized and the spinal cords were processed to evaluate lesion volume (BRS, SI).

\section{Treatment allocation}

For the first 28/35 rats, each day four rats underwent SCI and were allocated to one of the four treatment groups. For practical reasons-specifically, the length of time required to administer delayed hypothermia and rewarming - the first rat of the day was always assigned to the hypothermia group. Treatment allocation for the other three rats was determined by coin toss by an investigator not otherwise involved in the experiments. The final 7/35 rats were allocated to treatment groups in accordance with early mortality.

\section{Autonomic function}

Rectal temperature was measured using a digital thermometer (DT-610B; ATP Instrumentation, Leicestershire, UK). Heart rate was recorded using the MouseOx. Ipsilateral ptosis was determined by physical examination.

\section{Arousal (lethargy)}

The response to non-noxious whisker/face tactile stimulation was scored as follows: 0 , dead; 1 , alive but no response; 2 , weak response (moves head); 3 , strong response (moves head, neck, and forelimbs).

\section{Motor scores}

Motor function early after trauma was evaluated, with scores determined as follows ${ }^{33,34}$ : 0 , no movement of hind limbs, no weight bearing; 1 , barely perceptible movements of hind limbs, no weight bearing; 2 , frequent and/or vigorous movement of hindlimbs but no weight support; 3 , alternative stepping and propulsive movements of hind limbs, some intermittent weight bearing; 4, can support weight and walk with deficit apparent; 5, normal walking.

\section{Bladder function}

On two to three occasions per day, the bladder was palpated to determine fullness. When full, manual compression was applied to initiate emptying (Credé's maneuver). The appearance of the urine, whether grossly bloody or not, was recorded.

\section{Serum glucose}

Tail prick was used to obtain a droplet of blood; serum glucose was measured using a glucometer (OneTouch Ultra; LifeScan Inc., Milpitas, CA). 


\section{BBB scores}

$\mathrm{BBB}^{35}$ scores were determined as described, except that modifications were introduced to allow more accurate assessment of the functional asymmetry associated with hemicord injury. The scoring sheet shown in the original paper ${ }^{35}$ provides for scoring of the right and left hindlimbs separately, with the final score for the animal being based on the two scores. Here, because we were studying hemicord injuries, we maintained the two scores separately, which we refer to as mBBB scores. ${ }^{25,30}$ The method for scoring up to and including scores of 11 is identical for $\mathrm{mBBB}$ and BBB. For $\mathrm{mBBB}$ scoring of coordination, forelimb-hindlimb coordination was operationally defined as a one-to-one correspondence between forelimb and ipsilateral hindlimb steps on each side; "alternation in hindlimb stepping", which is taken into account in BBB scoring, was ignored for mBBB scoring. For scores above 19, both right and left sides were credited for "tail consistently up" and for "trunk stability." Serial mBBB scores were assessed by two independent investigators, with the worse of the two scores being used.

\section{Inclined plane}

We measured the angle of failure on up-angled and down-angled planes, using a wooden surface (unfinished Luan plywood), with the plane position angled from horizontal at $\sim 5^{\circ} / \mathrm{sec}^{36}$ The animals were placed transversely on the inclined plane and the highest angle the rat could maintain for $5 \mathrm{sec}$ was recorded. The better of two consecutive tests was taken as the final measure.

\section{Beam balance}

Performance on beam balance was evaluated, ${ }^{37}$ with scores determined as follows: 0 , falls off; 1 , hangs on; 2 , stands on beam but one or two legs slip off; 3 , stands on beam; 4, walks on beam.

\section{Accelerating rotarod}

Performance on the accelerating rotarod ${ }^{38}$ (IITC, Life Science, Woodland Hills, CA) was measured during the fifth week after SCI. The drum was started at $4 \mathrm{rpm}$ and was accelerated at rate of $2 \mathrm{rpm}$ every $5 \mathrm{sec}$ up to a maximum of $45 \mathrm{rpm}$. Three trials separated by 20 min were administered; we report the average latency to falling off of the drum.

\section{Lesion volume and spared spinal cord tissue}

At six weeks after SCI, the rats were deeply anesthetized, exanguinated, and transcardially perfusion-fixed with $10 \%$ neutral buffered formalin, and the spinal cords were harvested. Serial paraffin sections ( $10 \mu \mathrm{m}$ thickness) were prepared from $2 \mathrm{~cm}$ spinal cord segments encompassing the injury site. Sections were obtained every $500 \mu \mathrm{m}$ (no treatment group; $\sim 20$ sections/rat) or every $250 \mu \mathrm{m}$ (riluzole, hypothermia, and glibenclamide groups; $\sim 40$ sections/rat) and were mounted on glass slides. All sections were deparafinized and stained with hematoxylin and eosin (H\&E) as a single batch (Tissue-Tek Prisma/Film Automated Slide Stainer; Sakura, Torrance, CA). After coverslipping, the sections were scanned at 2400 dpi using a flatbed scanner. The file names of the images were encoded to de-identify treatment group identity. Photoshop CS6 (v 13.0 x64; Adobe Systems Inc., San Jose CA) was used to view the image of each section enlarged $\sim 40 \times$ and to draw planimetric lesion contours. ${ }^{39}$ Lesion boundaries were identified as abrupt reductions in $\mathrm{H} \& \mathrm{E}$ staining, compared with uninjured tissues. All contours outlining the lesion area and the area of spared spinal cord tissue were drawn by one researcher (BRS); ambiguous lesion boundaries were resolved by consensus between BRS and an experienced histopathologist (SI). Lesion volumes and volumes of spared spinal cord tissue (in $\mathrm{mm}^{3}$ ) were calculated as the sum of the areas (in $\mathrm{mm}^{2}$ ) multiplied by 0.5 or $0.25 \mathrm{~mm}$, as appropriate.

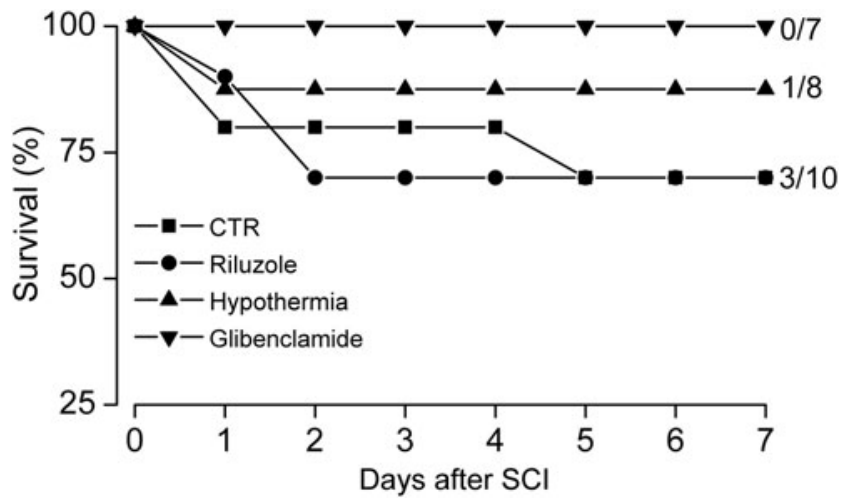

FIG. 1. Survival curves for the four groups. All deaths occurred during the first week after trauma. CTR, untreated controls; SCI, spinal cord injury. The apparent trend was not statistically significant.

\section{Data analysis}

Like BBB scores, ${ }^{40-42} \mathrm{mBBB}$ scores are derived from an ordinal scale and are not normally distributed, and so were analyzed using a nonparametric procedure. Modified BBB scores and beam balance scores at six weeks were analyzed using the Kruskal-Wallis test, with Dunn's post hoc comparison. Parametric data at six weeks, including performance on the inclined plane and accelerating rotarod, as well as body weight, lesion volumes, and volumes of spared spinal cord tissue, were analyzed using a one-way analysis of variance with Fisher's post hoc comparisons. All data, including scores, are presented as mean \pm standard error.
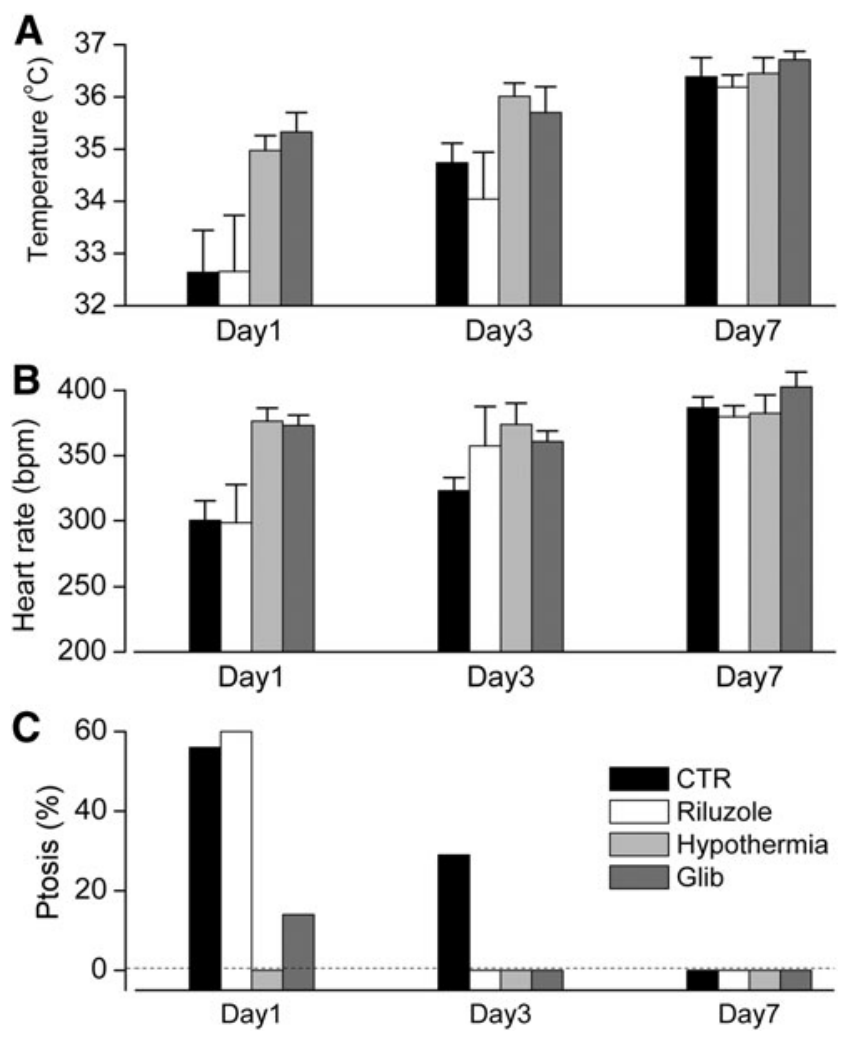

FIG. 2. Autonomic function. Rectal temperature (A), heart rate (B), and ipsilateral ptosis (C) were measured on Days 1, 3 and 7 in the four groups, as indicated. bpm, beats per minute; CTR, untreated controls; GLIB, glibenclamide. For all measures, values in the four groups converged by Day 7 . 

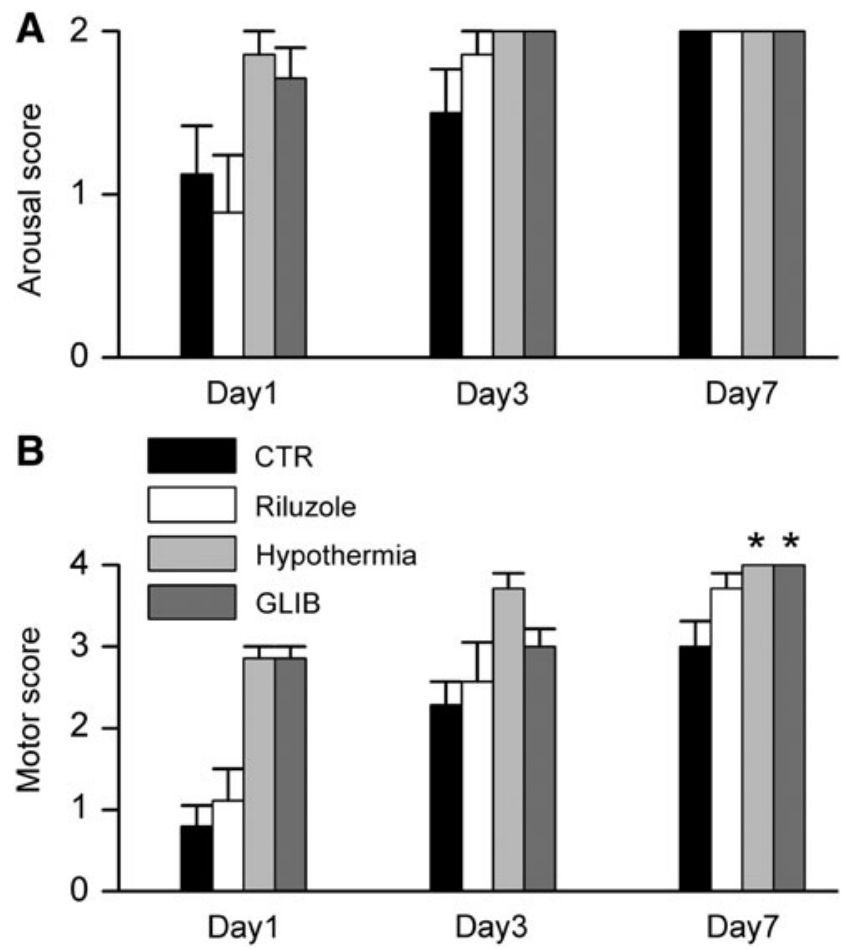

FIG. 3. Arousal scores and motor scores. Arousal scores (A) and motor scores (B) were measured on Days 1, 3, and 7 in the four groups, as indicated. CTR, untreated controls; GLIB, glibenclamide. For arousal scores at Day 7, values in the four groups converged; for motor scores at day 7, CTR vs. hypothermia and CTR vs. glibenclamide, both $p<0.05$; CTR vs. riluzole, $p>0.05$ by Kruskall-Wallis test with Dunn's post hoc comparisons.

\section{Results}

\section{Assessments during Phase 1 (Week 1 only)}

During the first week after trauma, when group identity could not be concealed (Phase 1, see Methods), we assessed mortality daily. Also, on Days 1, 3, and 7, we assessed autonomic function, arousal scores (lethargy), motor scores, bladder function, and serum glucose.

Mortality. Mortality in both the control and the riluzole groups was $30 \%$; one rat in the hypothermia group died during the night after the procedure. There were no deaths in the glibenclamide group (Fig. 1).
Autonomic function. On Days 1-3, bradycardia and spontaneous hypothermia were observed in the control and riluzole groups, but these abnormalities normalized by Day 7 . These abnormalities were not observed in the hypothermia or glibenclamide groups (Fig. 2A, 2B).

Ipsilateral ptosis is believed to reflect acute lesion expansion caudally from the lower cervical to the upper thoracic spinal cord, resulting in sympathetic dysfunction. Ptosis was present on Day 1 in 4/7 rats in both the control and the riluzole groups, in 1/7 rats in the glibenclamide group, and in none of the hypothermia group (Fig. 2C). By Day 3, 2/7 rats in the control group still exhibited ptosis, whereas none in the other groups did.

Arousal scores. The response to non-noxious whisker/face tactile stimulation was used to assess the level of arousal (degree of lethargy). On Day 1, scores were low for both the control and riluzole groups, whereas they were high (near normal) for both the hypothermia and glibenclamide groups (Fig. 3A). By Day 3, the riluzole group had normalized, whereas the controls had not.

Motor scores. On Day 1, motor scores for the control and riluzole groups indicated little if any movement of the hindlimbs, with a mean score of 1 , whereas the hypothermia and glibenclamide groups showed appreciable function, with a mean score of 3 (Fig. 3B). Scores improved in all groups with time, and by Day 7 , the three treatment groups performed better than controls.

Bladder function. Hematuria (hemorrhagic cystitis) may reflect involvement of the lateral funiculus. ${ }^{43}$ On Day 1 , hematuria was present in 3/9, 2/9, 1/7, 0/7 rats in the control, riluzole, hypothermia, and glibenclamide groups, respectively (Table 1). On Day 1, spontaneous unassisted voiding was present in $3 / 9,3 / 9,5 / 7,6 / 7$ rats in the control, riluzole, hypothermia, and glibenclamide groups, respectively (Table 1). By Day 7, all rats were voiding without assistance. ${ }^{44}$

Serum glucose. Serum glucose measured on days 1, 3, and 5 showed that rats in all treatment groups had values above $100 \mathrm{mg} / \mathrm{dL}$; only the control rats on Day 1 had lower values, $\sim 90 \mathrm{mg} / \mathrm{dL}$ (Fig. 4).

\section{Assessments spanning Phase 1 (Week 1) and Phase 2 (Weeks 2-6)}

Following the first week after trauma, group identity was concealed from evaluators (Phase 2; see Methods). During both Phase 1 and Phase 2, we assessed mBBB scores, performance on the inclined plane, and beam balance. At the end of Phase 2, we assessed performance on the accelerating rotarod

Table 1. Urinary Function

\begin{tabular}{|c|c|c|c|c|}
\hline & Control & Riluzole & Hypothermia & Glibenclamide \\
\hline Day 1 & $\begin{array}{l}\text { Credé: +hem } 3 / 9 \\
\text { Credé: -hem } 3 / 9 \\
\text { Spont: } 3 / 9\end{array}$ & $\begin{array}{l}\text { Credé: +hem 2/9 } \\
\text { Credé: -hem } 4 / 9 \\
\text { Spont: } 3 / 9\end{array}$ & $\begin{array}{l}\text { Credé: +hem 1/7 } \\
\text { Credé: -hem } 1 / 7 \\
\text { Spont: } 5 / 7\end{array}$ & $\begin{array}{l}\text { Credé: +hem 0/7 } \\
\text { Credé: -hem 1/7 } \\
\text { Spont: } 6 / 7\end{array}$ \\
\hline Day 3 & $\begin{array}{l}\text { Credé: +hem 0/8 } \\
\text { Credé: -hem } 1 / 8 \\
\text { Spont: } 7 / 8\end{array}$ & $\begin{array}{l}\text { Credé: +hem 1/7 } \\
\text { Credé: -hem 2/7 } \\
\text { Spont: } 4 / 7\end{array}$ & $\begin{array}{l}\text { Credé: +hem 0/7 } \\
\text { Credé: -hem 0/7 } \\
\text { Spont: } 7 / 7\end{array}$ & $\begin{array}{l}\text { Credé: +hem 0/7 } \\
\text { Credé: -hem 0/7 } \\
\text { Spont: } 7 / 7\end{array}$ \\
\hline Day 7 & $\begin{array}{l}\text { Credé: +hem 0/7 } \\
\text { Credé: -hem 0/7 } \\
\text { Spont: } 7 / 7\end{array}$ & $\begin{array}{l}\text { Credé: +hem 0/7 } \\
\text { Credé: -hem 0/7 } \\
\text { Spont: } 7 / 7\end{array}$ & $\begin{array}{l}\text { Credé: +hem 0/7 } \\
\text { Credé: -hem 0/7 } \\
\text { Spont: } 7 / 7\end{array}$ & $\begin{array}{l}\text { Credé: +hem 0/7 } \\
\text { Credé: -hem 0/7 } \\
\text { Spont: } 7 / 7\end{array}$ \\
\hline
\end{tabular}

Credé: +hem, Credé's maneuver required to express bladder yields bloody urine;Credé: -hem, Credé's maneuver required to express bladder but urine not grossly bloody; Spon, spontaneous voiding; no need to express the bladder. 


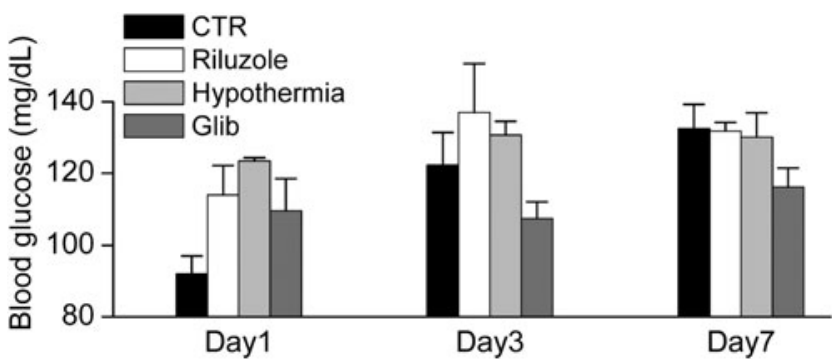

FIG. 4. Serum glucose. Serum glucose levels were measured on Days 1, 3, and 7 in the four groups, as indicated. For the data at day $7, p=0.15$ by one-way analysis of variance.

mBBB scores. The model we used with unilateral cervical SCI resulted in asymmetric hindlimb locomotor function, which we assessed using an mBBB scoring system that maintained the scoring for each hindlimb separately (see Methods and References) ${ }^{25,30}$

Throughout the six weeks of testing, scores for both the ipsilateral and contralateral hindlimbs were largely similar for the hypothermia and glibenclamide groups, showing uninterrupted improvements in function with time (Fig. 5A). For the first two weeks after trauma, scores for riluzole-treated rats lagged those in the hypothermia and glibenclamide groups, but subsequently their scores joined those of the other two treatment groups. During the last four weeks, scores in the three treatment groups were similar and were significantly better than controls.

Inclined plane. Similar to the $\mathrm{mBBB}$ scores, throughout the six weeks of testing, performance on the up-angled and downangled inclined plane were largely similar for the hypothermia and glibenclamide groups (Fig. 5B). Performance for the control and riluzole groups was similar initially but the riluzole group improved rapidly after Week 2 . During the last weeks, the performances in all groups were similar.

Beam balance. This is a test of coordinated forelimb and hindlimb function. Scores were largely similar for the hypothermia and glibenclamide groups, showing uninterrupted improvements throughout the six weeks of testing (Fig. 6A). Scores
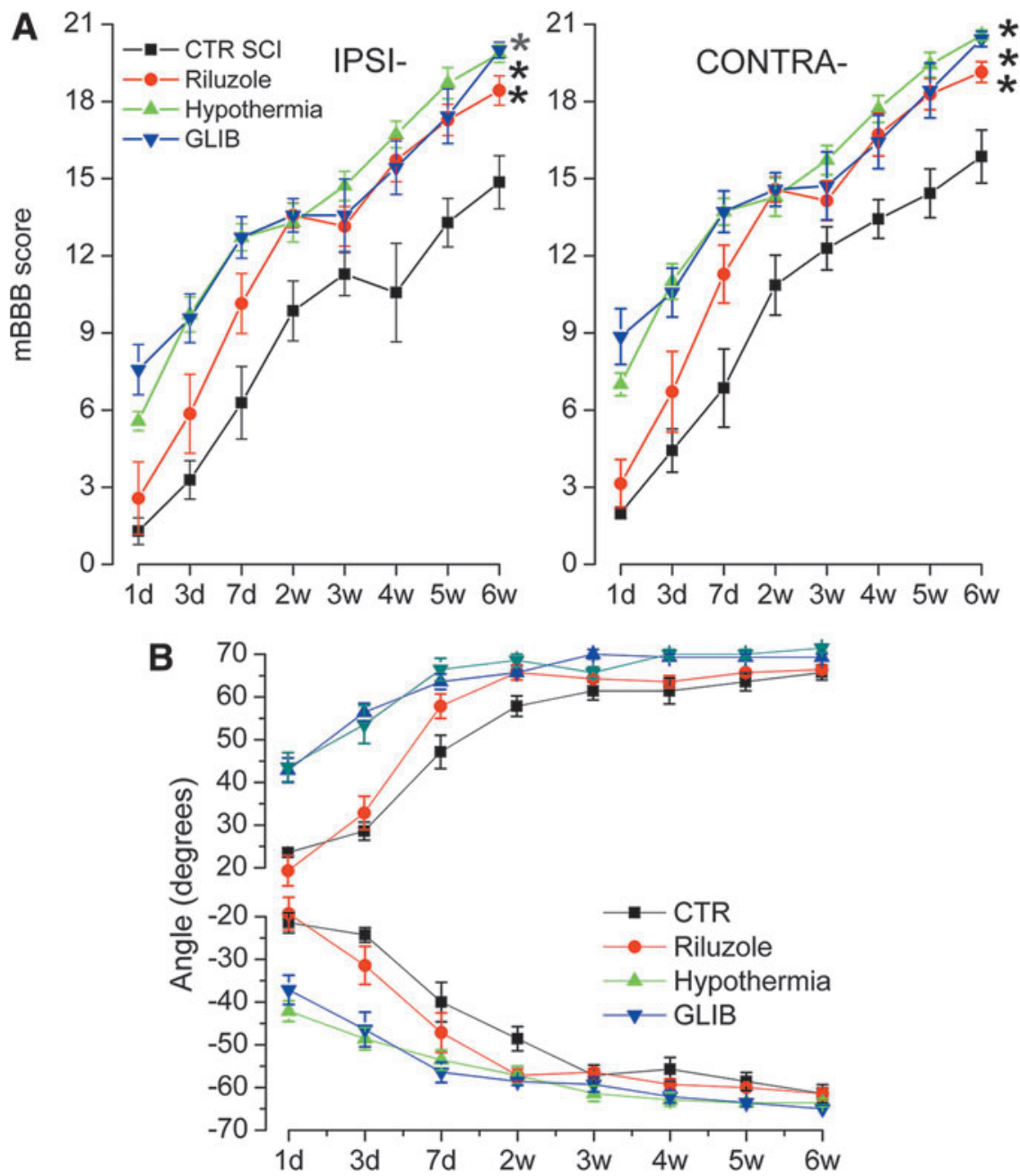

FIG. 5. Modified Basso, Beattie, and Bresnahan (mBBB) scores and angled plane. Modified BBB scores for the ipsilateral and contralateral hindlimb (A), and performance on the up-angled and down-angled inclined plane (B) were measured on Days 1, 3, and 7 and at weekly intervals thereafter in the four groups, as indicated. For the ipsilateral and contralateral mBBB scores at six weeks: untreated controls (CTR) vs. riluzole, CTR vs. hypothermia, and CTR vs. glibenclamide, all $p<0.05$ by Kruskall-Wallis test with Dunn's post hoc comparisons. For the inclined plane data at six weeks: CTR vs. riluzole, CTR vs. hypothermia, and CTR vs. glibenclamide, all $p>0.05$, by one-way analysis with Fisher's post hoc comparisons. Color image is available online at www.liebertpub.com/neu 

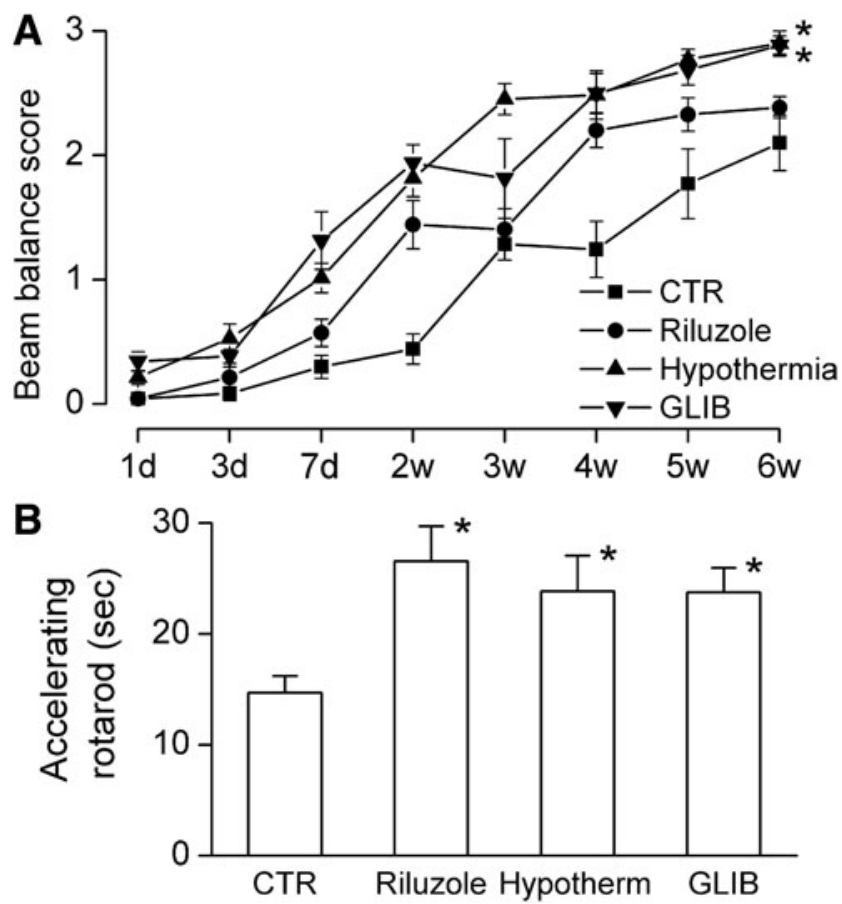

FIG. 6. Beam balance scores and accelerating rotarod. (A) Performance on beam balance was measured on Days 1, 3, and 7 and at weekly intervals thereafter in the four groups, as indicated. For the data at six weeks: untreated controls (CTR) vs. hypothermia and CTR vs. glibenclamide, both $p<0.05$; CTR vs. riluzole, $p>0.05$, by Kruskall-Wallis test with Dunn's post hoc comparisons. (B) Performance on the accelerating rotarod was measured during the fifth week in the four groups, as indicated; CTR vs. riluzole, CTR vs. hypothermia, and CTR vs. glibenclamide, all $p<0.05$ by one-way analysis of variance with Fisher's post hoc comparisons.

for the riluzole group lagged behind those of the other two treatment groups throughout the six weeks, and at six weeks, were significantly different from the hypothermia and glibenclamide groups.

Accelerating rotarod. This is another test of coordinated forelimb and hindlimb function. Performance on the accelerating rotarod was assessed once during the fifth week after trauma. On this measure, rats in the three treatment groups performed similarly, and they performed significantly better than controls (Fig. 6B).

\section{Body mass}

Normal weight gain in young adult rats is an important measure of general well-being, which is known to be impaired after SCI. ${ }^{45}$ Body mass was measured before trauma, on Days 1, 3, and 7 after trauma, then weekly thereafter. Rats in all groups lost weight during the first week after trauma, with rats in the glibenclamide group losing the least and recovering the quickest (Fig. 7). After the first week, all rats resumed weight gain, but body weight in glibenclamide-treated rats continued to be significantly greater than in control, riluzole-treated, and hypothermia-treated rats.

\section{Lesion volume and spared spinal cord tissue}

At the end of the six-week period of testing, the rats were euthanized and the spinal cords were processed to measure lesion

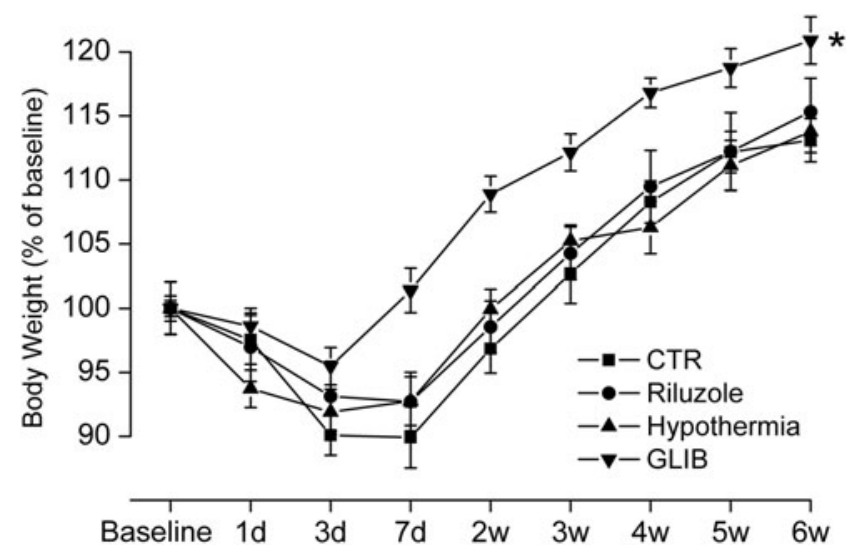

FIG. 7. Body weight. Body weights were measured at baseline, on Days 1, 3, and 7 and at weekly intervals thereafter in the four groups, as indicated. For the data at six weeks: glibenclamide vs. untreated controls (CTR) and glibenclamide vs. hypothermia, $p<0.05$; glibenclamide vs. riluzole $p>0.05$ by one-way analysis of variance with Fisher's post hoc comparisons.

volumes and spared spinal cord tissue. Areas were measured on serial H\&E sections (Fig. 8A). Areas were plotted as a function of distance from the epicenter, and were used to calculate volumes (Fig. 8B, 8C). Lesion volumes were: $4.8 \pm 0.7,3.5 \pm 0.4,3.1 \pm 0.3$ and $2.5 \pm 0.3 \mathrm{~mm}^{3}$ in the control, riluzole, hypothermia, and glibenclamide groups, respectively. Volumes of spared spinal cord tissue were: $13.8 \pm 0.8$, $15.9 \pm 0.8,17.1 \pm 0.5$, and $17.7 \pm 0.8 \mathrm{~mm}^{3}$ in the control, riluzole, hypothermia, and glibenclamide groups, respectively. Notably, some degree of atrophy of the cervical spinal cord rostral to the lesion was identified in all but the glibenclamide group.

\section{Discussion}

Important advances have been made in the design of preclinical trials aimed at identifying safe and effective treatments for SCI. The National Institutes of Neurological Diseases and Stroke established Facilities of Research Excellence in Spinal Cord Injury (FORE-SCI) sites to address key factors that have hampered the translation of research on promising new therapeutics from the laboratory to clinical trials. FORE-SCI sites provide training on best practices, and attempt to replicate novel experimental therapeutic studies in SCI models. Notably, this effort led to the finding that published studies are difficult to replicate, ${ }^{24,46,47}$ and that successful replication can be complex. ${ }^{48}$ Recently, the consortium on MIASCI proposed reporting standards for preclinical SCI experiments, ${ }^{29}$ recommending the adoption of uniform reporting standards, such as common data elements (data elements used in multiple clinical studies) and minimum information standards. Although these efforts are essential, they do not directly address the urgent need to identify the best among a group of candidate therapies, to help assure that the immense efforts required and the limited resources available for clinical trials are focused appropriately, and to help assure that the enormous suffering incurred by the victims of SCI is addressed in as timely and robust a manner as possible.

One approach to the problem of identifying the best among a group of candidate therapies is to perform a direct comparison of the different therapies in a single experiment in one laboratory. ${ }^{30}$ With this approach, all treatments are evaluated concurrently, with direct comparison of the efficacy of different treatments performed in a standardized environment, with a minimum of variability in 
A

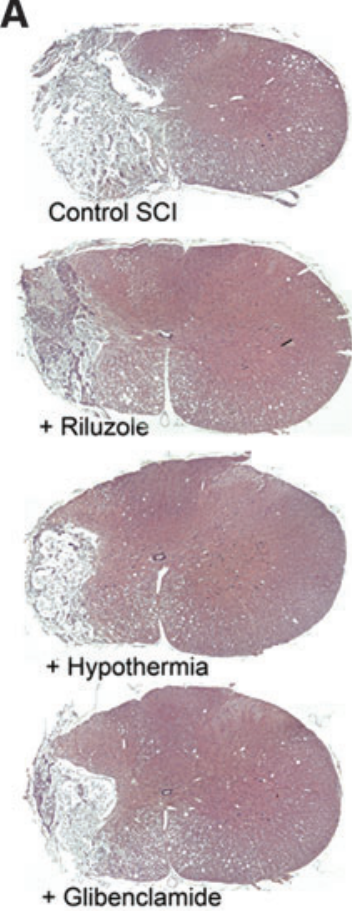

B

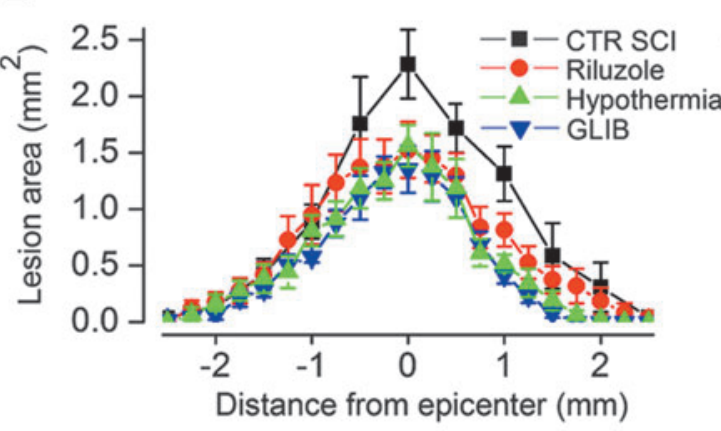

C

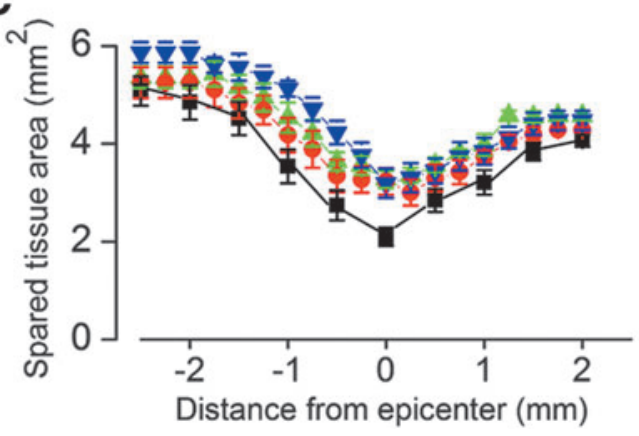

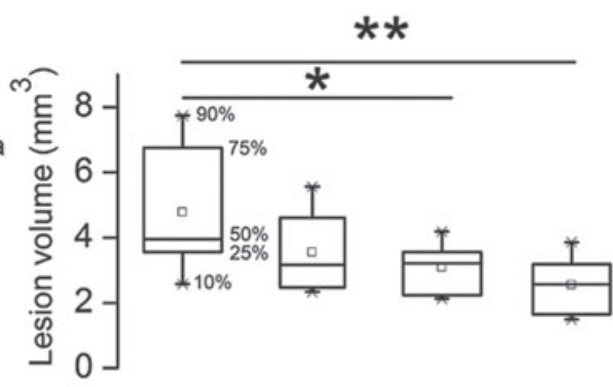

CTR Riluzole Hypotherm. GLIB

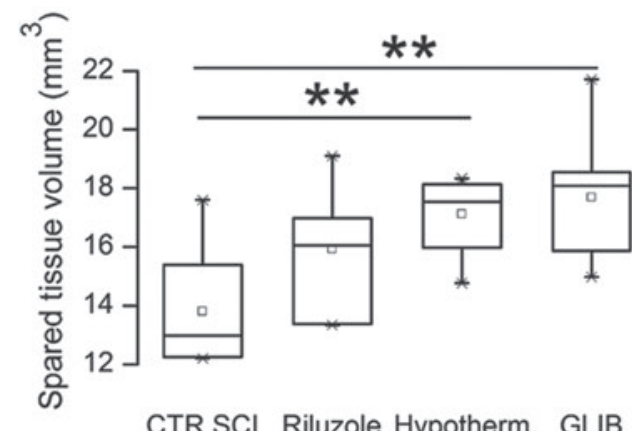

FIG. 8. Lesion sizes and size of spared spinal cord tissue. (A) Hematoxylin and eosin-stained coronal sections obtained at the epicenter of injury from representative spinal cords six weeks after trauma in each of the four groups, as indicated. (B) Lesion areas as a function of distance from the epicenter (left) and box plots of lesion volumes (right) for each of the four groups, as indicated; negative numbers, rostral; small square, mean; percentiles as indicated; untreated controls (CTR) vs. riluzole, $p>0.05$; CTR vs. hypothermia, $p<0.05(*)$; CTR vs. glibenclamide, $p<0.01(* *)$; by one-way analysis of variance (ANOVA) with Fisher's post hoc comparisons. (C) Area of spared spinal cord tissue as a function of distance from the epicenter (left) and box plots of spared spinal cord tissue volumes (right) for each of the four groups, as indicated; CTR vs. riluzole, $p>0.05$; CTR vs. hypothermia and CTR vs. glibenclamide, both $p<0.01\left(^{* *}\right)$; by one-way ANOVA with Fisher's post hoc comparisons. Color image is available online at www.liebertpub.com/neu

surgery, animal care, outcome evaluation, and other variables. The principal difficulty with this approach is the potential for bias, but bias can be managed effectively by evaluating objective (along with subjective) measures, and by concealing treatment group identity from those evaluating outcomes, as we did here.

In the present study, we performed a direct comparison of riluzole, ${ }^{15-19}$ systemic hypothermia ${ }^{20-23}$ and glibenclamide. ${ }^{8,9,12,24-26}$ Despite the high quality of the published research on these treatments, there previously was no reliable way to compare them in terms of efficacy (i.e., to judge which might be better) since different models were used, different laboratories were involved, and different outcomes may have been evaluated. ${ }^{27}$ Similarly, there was no way to compare the three in terms of safety, given that each has its own treatment-associated complications or untoward side-effects, especially in the context of injury. Here, we directly compared riluzole, systemic hypothermia, and glibenclamide in a single experiment; moreover, a wide variety of treatment and safety outcome measures were evaluated by investigators who were blinded to treatment group identity during all but the first week after trauma.

With regard to efficacy, the direct comparisons that we made between treatments were revealing. All three treatments showed overall favorable results, compared with controls, in keeping with previously published reports. On the outcome measure that is used routinely in preclinical SCI research-the BBB score-the three treatments demonstrated similar efficacy at six weeks, with all three being significantly better than controls. The hypothermia- and glibenclamide-treated animals were largely indistinguishable throughout the entire study. Riluzole-treated rats underperformed for the first two weeks but then joined the hypothermia and glibenclamide groups, and the three treatments became almost indistinguishable by six weeks. However, on beam balance, which assesses cervical lower motor neuron function, as well as lower extremity function, hypothermia and glibenclamide treatments showed significant advantages over riluzole. A better performance with glibenclamide also was found in our previous study comparing riluzole and glibenclamide, in which a larger impact force, lower doses of both drugs, and an earlier treatment time were used. ${ }^{30}$

Lesion volumes at six weeks, which reflect in part acute lesion expansion, were smaller in all treatment groups, compared with controls, again in keeping with previously published reports. The control, riluzole, hypothermia, and glibenclamide groups, in that order, exhibited the largest to the smallest lesion volumes. Whereas the effects of hypothermia and glibenclamide reached statistical significance, compared with control, that of riluzole did not. These differences in lesion volumes were reflected in complementary measurements of spared spinal cord tissue, which showed, in addition, some degree of atrophy of the spinal cord rostral to the lesion in all groups except the glibenclamide group. The lack of statistical significance with riluzole may have been due to the small sample size or to the delay of $4 \mathrm{~h}$ before the start of treatment; in our previous report, treatment with riluzole at $3 \mathrm{~h}$ yielded a significant reduction in lesion volume. ${ }^{30}$ Notably, a more favorable effect on lesion size with glibenclamide, compared with riluzole, was found both here and in our previous study. ${ }^{30}$

As noted above, the mBBB scores in the three treatment groups were similar during the final weeks of evaluation, despite substantive differences in lesion volumes. These observations are consistent with reports that spontaneous recovery of hindlimb 
function in rats after SCI is fairly robust, and that appreciable recovery can occur even with little sparing of spinal cord white matter. ${ }^{49,50}$ Because of this natural tendency toward recovery of hindlimb function in rats with moderate cervical SCI, BBB scores are limited by a "ceiling effect" that fails to reflect the true magnitude of pathological involvement. ${ }^{51}$ Importantly, the BBB scoring system was designed to evaluate midline lower thoracic injuries, not unilateral lower cervical injuries. With precisely placed lower cervical injuries, as we did here (see Methods), tests assessing upper extremity function in isolation, such as grip strength $^{30}$ and various other forelimb tests, ${ }^{52-56}$ or the coordinated function of all four limbs, such as the beam balance, as well as lesion volumes themselves, may be more appropriate than BBB scores for identifying the best among a group of candidate therapies. This assertion is supported by our data here on beam balance and lesion volumes; of the functional tests measured, lesion volumes correlated best with the beam balance data.

When considering patient care, safety concerns are as important as any outcome measure. Notably, safety issues discriminated strongly between the different treatments. Foremost was the treatment-associated mortality of $30 \%(3 / 10), 30 \%(3 / 10), 12.5 \%$ $(1 / 8)$, and $0 \%(0 / 7)$ in the control, riluzole, hypothermia, and glibenclamide groups, respectively. The single death in the hypothermia group could have been due to our inexperience with this procedure. Other studies with moderate systemic hypothermia have not reported treatment-associated deaths. ${ }^{20,21,23}$

The mortality with riluzole, however, reflects the well-known unfavorable therapeutic index of this compound, specifically in the context of cervical SCI. Wu and colleagues ${ }^{18,19}$ reported that rats with cervical SCI receiving a dose of $8 \mathrm{mg} / \mathrm{kg}$ IP twice daily had marked lethargy, respiratory distress and $70 \%$ (7/10 rats) mortality; those administered $6 \mathrm{mg} / \mathrm{kg}$ IP twice daily had 8\% (2/26) mortality, and those administered $4 \mathrm{mg} / \mathrm{kg}$ IP twice daily had minimal lethargy and $0 \%$ mortality. Here, we used a dose of $5 \mathrm{mg} / \mathrm{kg}$ IP twice daily, and observed marked lethargy and 30\% mortality, whereas previously, we used a dose of $2.5 \mathrm{mg} / \mathrm{kg}$ IP twice daily and had minimal lethargy and $0 \%$ mortality. ${ }^{30}$ Notably, even the highest of these doses is well tolerated and produces no untoward effects, including no lethargy or mortality in normal, uninjured rats. ${ }^{19} \mathrm{We}$ speculate that the reason for this toxicity, specifically in animals with lower cervical SCI, may relate to the massive opening of the blood-brain barrier in the area of injury; if the injury is near the portion of the spinal cord controlling critical respiratory or autonomic functions, ion channels that are required to sustain life may be inhibited inadvertently. At micromolar concentrations (IC50, $3-10 \mu \mathrm{M})$, riluzole is a relatively selective blocker of persistent sodium currents in neurons, including spinal cord neurons. ${ }^{57-61}$ That rats with lower cervical SCI may be selectively vulnerable to riluzole is consistent with the observation that studies on rats with lower thoracic-level SCI treated with riluzole report no treatmentassociated mortality. ${ }^{15,17}$ Insofar as most SCI in humans involves the cervical spinal cord, it would seem prudent that preclinical studies should demonstrate negligible treatment-associated morbidity and mortality, specifically in cervical SCI. Compounding cervical SCI with respiratory or autonomic depression clearly is undesirable.

Apart from lethargy and mortality, we also evaluated other potential safety concerns. Because glibenclamide increases insulin secretion from the pancreas, we measured serum glucose levels. We found that in all treatment groups, including the glibenclamide group, levels above $100 \mathrm{mg} / \mathrm{dL}$ were maintained at all times, consistent with prior reports that constant infusion of low-dose glibenclamide does not produce hypoglycemia., ${ }^{8,62}$ Post-treatment autonomic functions including ptosis, heart rate, and rectal temperature also were monitored. On these measures, the hypothermia and glibenclamide groups were similar and favorable, whereas ptosis, spontaneous hypothermia, and bradycardia were prevalent in the riluzole and control groups early on, although they tended to recover by Day 7 . Spontaneous voiding was present in 5/7 and 6/7 rats in the hypothermia and glibenclamide groups on Day 1 , and in only half as many in the control and riluzole groups. Hematuria (hemorrhagic cystitis) was most prevalent in the riluzole and control groups early on.

Do observations on safety in rats predict safety issues in humans with SCI? To date, the experience with riluzole, systemic hypothermia, and glibenclamide in humans with acute CNS injury is limited. In a Phase 1 trial of riluzole in SCI involving 36 patients, no major safety issues were reported. ${ }^{63}$ However, the dose studied in humans (50 mg PO twice daily, i.e., $\sim 1.43 \mathrm{mg} / \mathrm{kg} / \mathrm{d}$ ) was considerably smaller than the doses used in the preclinical studies on rats that demonstrated not only efficacy but also significant toxicity. Investigators at the Miami Project to Cure $\mathrm{Pa}$ ralysis reported on 35 patients with cervical SCI who were treated with operative decompression and stabilization followed by $48 \mathrm{~h}$ of modest $\left(32-34^{\circ} \mathrm{C}\right)$ systemic hypothermia via an intravascular cooling catheter. ${ }^{64,65}$ Their experience was favorable, although they used a longer treatment time than in the preclinical studies, and general inhalation anesthesia was not used during hypothermia in the patients, whereas it was in the preclinical studies. Complications included an increased incidence of pulmonary problems (such as effusions), anemia, and venous thromboembolic events. No data are available on the use of glibenclamide in human SCI, but in 10 patients with large malignant strokes, RP1127 (glyburide for injection; $3 \mathrm{mg} / \mathrm{d}$ intravenously; i.e., $0.043 \mathrm{mg} / \mathrm{kg} / \mathrm{d}$ ) produced no symptomatic hypoglycemia or other untoward complications, and was found to be safe. ${ }^{66}$ It remains to be seen how these three treatments will compare in terms of safety in humans with cervical SCI, especially at doses that can be shown to be therapeutic.

Malnutrition is a well-recognized threat to proper healing and to general well-being after trauma. In both humans and animal models, SCI is accompanied by prolonged post-injury loss of body weight, including fat mass. ${ }^{45,67}$ Hypoproteinemia and malnutrition are significant predictors of mortality in patients with cervical SCI. ${ }^{68,69}$ An intriguing observation from the present study is that rats in the glibenclamide group lost comparatively little weight and rapidly returned to a normal pattern of weight gain, a finding that differed markedly and significantly from all other groups. Post-injury loss of body weight, including fat mass, is not due to hypophagia but possibly to changes in gastrointestinal transit and absorption, as well as metabolic-associated disorders, such as glucose intolerance, insulin resistance, and lipid abnormalities. ${ }^{45,70}$ Glibenclamide is known to act not only on pancreatic $\beta$ cells to stimulate insulin release but it also acts on white (pre)adipocytes to induce differentiation and stimulate the production of adiponectin, an insulin-sensitizing hormone, via activation of PPAR $\gamma{ }^{71,72}$ Together, these effects of glibenclamide result in lipogenic and antilipolytic effects ${ }^{73}$ associated with weight gain. ${ }^{74}$ This unexpected salutary effect of glibenclamide in SCI merits further investigation.

Finally, the ease of administration of a given treatment is worthy of consideration. In a hospital setting, administering a drug, especially intravenously, is less invasive, and requires fewer resources and less effort by health care professionals than inducing and maintaining systemic hypothermia. In patients that 
must undergo surgery for SCI, the norm thus far has been to start the systemic hypothermia treatment after surgery, ${ }^{64,65}$ a restriction that does not apply to IV drug infusion. Moreover, multitrauma patients with SCI typically require concurrent treatments, surgeries or diagnostic imaging procedures that may interfere with administering systemic hypothermia but are less likely to interfere with an IV drug infusion.

In summary, the data reported here reaffirm that riluzole, systemic hypothermia, and glibenclamide are strong candidates for translation to clinical trials in SCI. With regard to safety and efficacy (lesion volume), systemic hypothermia and glibenclamide appear to be superior to riluzole. With regard to safety, efficacy, general well-being, and ease of administration, glibenclamide appears to be superior to riluzole and systemic hypothermia.

\section{Acknowledgments}

This work was supported by grants to JMS from the Veterans Administration (Baltimore), the National Institute of Neurological Disorders and Stroke (NINDS; NS060801); to VG from NINDS (NS061934); to PGP from NINDS (HHSN271200800040C) and the Ray W. Poppleton endowment (OSU); to PGP and JMS from the Department of the Army (W81XWH 1010898); and to HH from the American Association of Neurological Surgeons. We thank Dr. W. Dalton Dietrich (Miami Project to Cure Paralysis) for his invaluable assistance with the hypothermia protocol.

\section{Author Disclosure Statement}

JMS holds a U.S. patent $(\# 7,872,048)$, "Methods for treating spinal cord injury with a compound that inhibits a $\mathrm{NC}(\mathrm{Ca}-\mathrm{ATP})$ channel." JMS is a member of the scientific advisory board and holds shares in Remedy Pharmaceuticals. No support, direct or indirect, was provided to JMS, or for this project, by Remedy Pharmaceuticals.

\section{References}

1. Wyndaele, M. and Wyndaele, J.J. (2006). Incidence, prevalence and epidemiology of spinal cord injury: what learns a worldwide literature survey? Spinal Cord. 44, 523-529.

2. Wyndaele, J. J. (2011). More knowledge of worldwide incidence and epidemiology of spinal cord injury: data from the United States military. Spinal Cord. 49, 857.

3. Participants, Paralysis Consensus Conference, Christopher and Dana Reeve Foundation. One degree of separation; paralysis and spinal cord injury in the United States. Christopher and Dana Reeve Foundation 2014 December 5; Available at: www.christopherreeve.org/atf/cf/ \%7B3d83418f-b967-4c18-8ada-adc2e5355071\%7D/8112REPTFINAL .PDF. Accessed June 21, 2015.

4. Spinal cord injury (SCI) fact sheet. Centers for Disease Prevention and Control 2014 December 5; Available at: http://manoa.hawaii.edu/pbrrtc/ wp-content/uploads/2014/12/SpinalCordInjuryFactsheet.pdf. Accessed December 5, 2014

5. Schoenfeld, A. J., Sielski, B., Rivera, K.P., Bader, J.O., and Harris, M.B. (2012). Epidemiology of cervical spine fractures in the US military. Spine J. 12, 777-783

6. Benton, R. L. and Hagg, T. (2011). Vascular Pathology as a Potential Therapeutic Target in SCI. Transl. Stroke Res. 2, 556-574.

7. Fassbender, J. M., Whittemore, S.R., and Hagg, T. (2011). Targeting microvasculature for neuroprotection after SCI. Neurotherapeutics. 8, 240-251

8. Simard, J. M., Tsymbalyuk, O., Ivanov, A., Ivanova, S., Bhatta, S., Geng, Z., Woo, S.K., and Gerzanich, V. (2007). Endothelial sulfonylurea receptor 1-regulated NC Ca-ATP channels mediate progressive hemorrhagic necrosis following spinal cord injury. J. Clin. Invest 117, 2105-2113.

9. Simard, J. M., Popovich, P.G., Tsymbalyuk, O., Caridi, J., Gullapalli, R.P., Kilbourne, M.J., and Gerzanich, V. (2013). MRI evidence that glibenclamide reduces acute lesion expansion in a rat model of spinal cord injury. Spinal Cord. 51, 823-827.

10. Bilgen, M., Abbe, R., Liu, S.J., and Narayana, P.A. (2000). Spatial and temporal evolution of hemorrhage in the hyperacute phase of experimental spinal cord injury: in vivo magnetic resonance imaging. Magn Reson. Med. 43, 594-600.

11. Aarabi, B., Simard, J.M., Kufera, J.A., Alexander, M., Zacherl, K.M., Mirvis, S.E., Shanmuganathan, K., Schwartzbauer, G., Maulucci, C.M., Slavin, J., Ali, K., Massetti, J., and Eisenberg, H.M. (2012). Intramedullary lesion expansion on magnetic resonance imaging in patients with motor complete cervical spinal cord injury. J. Neurosurg. Spine 17, 243-250.

12. Simard, J. M., Woo, S.K., Norenberg, M.D., Tosun, C., Chen, Z., Ivanova, S., Tsymbalyuk, O., Bryan, J., Landsman, D., and Gerzanich, V. (2010). Brief suppression of Abcc 8 prevents autodestruction of spinal cord after trauma. Sci. Transl. Med. 2, 28ra29.

13. Woo, S. K., Kwon, M.S., Ivanov, A., Gerzanich, V., and Simard, J.M. (2013). The sulfonylurea receptor 1 (Sur1)-transient receptor potential melastatin 4 (Trpm4) channel. J. Biol. Chem. 288, 3655-3667.

14. Simard, J. M., Woo, S.K., Aarabi, B., and Gerzanich, V. (2013). The Sur1-Trpm4 Channel in Spinal Cord Injury. J. Spine Suppl 4 pii, 002.

15. Stutzmann, J. M., Pratt, J., Boraud, T., and Gross, C. (1996). The effect of riluzole on post-traumatic spinal cord injury in the rat Neuroreport 7, 387-392.

16. Schwartz, G. and Fehlings, M.G. (2001). Evaluation of the neuroprotective effects of sodium channel blockers after spinal cord injury: improved behavioral and neuroanatomical recovery with riluzole. J. Neurosurg. 94, 245-256.

17. Ates, O., Cayli, S.R., Gurses, I., Turkoz, Y., Tarim, O., Cakir, C.O., and Kocak, A. (2007). Comparative neuroprotective effect of sodium channel blockers after experimental spinal cord injury. J. Clin. Neurosci. 14, 658-665.

18. Wu, Y., Satkundrarajah, K., Teng, Y., Chow, D.S., and Fehlings, M.G. (2010). Evaluation of the sodium-glutamate blocker riluzole in a preclinical model of cervical spinal cord injury. Evid. Based Spine Care J. 1, 71-72.

19. Wu, Y., Satkunendrarajah, K., Teng, Y., Chow, D.S., Buttigieg, J., and Fehlings, M.G. (2013). Delayed post-injury administration of riluzole is neuroprotective in a preclinical rodent model of cervical spinal cord injury. J. Neurotrauma 30, 441-452.

20. Yu, C. G., Jimenez, O., Marcillo, A.E., Weider, B., Bangerter, K., Dietrich, W.D., Castro, S., and Yezierski, R.P. (2000). Beneficial effects of modest systemic hypothermia on locomotor function and histopathological damage following contusion-induced spinal cord injury in rats. J. Neurosurg. 93, 85-93.

21. Lo, T. P., Jr., Cho, K.S., Garg, M.S., Lynch, M.P., Marcillo, A.E., Koivisto, D.L., Stagg, M., Abril, R.M., Patel, S., Dietrich, W.D., and Pearse, D.D. (2009). Systemic hypothermia improves histological and functional outcome after cervical spinal cord contusion in rats. J. Comp Neurol. 514, 433-448.

22. Ok, J. H., Kim, Y.H., and Ha, K.Y. (2012). Neuroprotective effects of hypothermia after spinal cord injury in rats: comparative study between epidural hypothermia and systemic hypothermia. Spine (Phila. Pa. 1976.) 37, E1551-E1559.

23. Grulova, I., Slovinska, L., Nagyova, M., Cizek, M., and Cizkova, D. (2013). The effect of hypothermia on sensory-motor function and tissue sparing after spinal cord injury. Spine J. 13, 1881-1891.

24. Popovich, P. G., Lemeshow, S., Gensel, J.C., and Tovar, C.A. (2011). Independent evaluation of the effects of glibenclamide on reducing progressive hemorrhagic necrosis after cervical spinal cord injury. Exp. Neurol. 233, 615-622.

25. Simard, J. M., Popovich, P.G., Tsymbalyuk, O., and Gerzanich, V. (2012). Spinal cord injury with unilateral versus bilateral primary hemorrhage-effects of glibenclamide. Exp. Neurol. 233, 829-835.

26. Redondo-Castro, E., Hernandez, J., Mahy, N., and Navarro, X. (2013). Phagocytic microglial phenotype induced by glibenclamide improves functional recovery but worsens hyperalgesia after spinal cord injury in adult rats. Eur. J. Neurosci. 38, 3786-3798.

27. Kwon, B. K., Okon, E., Hillyer, J., Mann, C., Baptiste, D., Weaver, L.C., Fehlings, M.G., and Tetzlaff, W. (2011). A systematic review of non-invasive pharmacologic neuroprotective treatments for acute spinal cord injury. J. Neurotrauma 28, 1545-1588.

28. Kilkenny, C., Browne, W.J., Cuthill, I.C., Emerson, M., and Altman, D.G. (2010). Improving bioscience research reporting: the ARRIVE guidelines for reporting animal research. PLoS. Biol. 8, e1000412. 
29. Lemmon, V. P., Ferguson, A.R., Popovich, P.G., Xu, X.M., Snow, D.M., Igarashi, M., Beattie, C.E., and Bixby, J.L. (2014). Minimum Information about a Spinal Cord Injury Experiment: A Proposed Reporting Standard for Spinal Cord Injury Experiments. J. Neurotrauma 31, 1354-1361.

30. Simard, J. M., Tsymbalyuk, O., Keledjian, K., Ivanov, A., Ivanova, S., and Gerzanich, V. (2012). Comparative effects of glibenclamide and riluzole in a rat model of severe cervical spinal cord injury. Exp. Neurol. 233, 566-574.

31. Simard, J. M., Woo, S.K., Tsymbalyuk, N., Voloshyn, O., Yurovsky, V., Ivanova, S., Lee, R., and Gerzanich, V. (2012). Glibenclamide-10$\mathrm{h}$ Treatment Window in a Clinically Relevant Model of Stroke. Transl. Stroke Res. 3, 286-295.

32. Engesser-Cesar, C., Anderson, A.J., Basso, D.M., Edgerton, V.R., and Cotman, C.W. (2005). Voluntary wheel running improves recovery from a moderate spinal cord injury. J. Neurotrauma 22, 157-171.

33. Gale, K., Kerasidis, H., and Wrathall, J.R. (1985). Spinal cord contusion in the rat: behavioral analysis of functional neurologic impairment. Exp. Neurol. 88, 123-134.

34. Westergren, H., Farooque, M., Olsson, Y., and Holtz, A. (2000). Motor function changes in the rat following severe spinal cord injury. Does treatment with moderate systemic hypothermia improve functional outcome? Acta Neurochir. (Wien.) 142, 567-573.

35. Basso, D. M., Beattie, M.S., and Bresnahan, J.C. (1995). A sensitive and reliable locomotor rating scale for open field testing in rats. J. Neurotrauma 12, 1-21.

36. Rivlin, A. S. and Tator, C.H. (1977). Objective clinical assessment of motor function after experimental spinal cord injury in the rat. J. Neurosurg. 47, 577-581.

37. von Euler, M., Akesson, E., Samuelsson, E.B., Seiger, A., and Sundstrom, E. (1996). Motor performance score: a new algorithm for accurate behavioral testing of spinal cord injury in rats. Exp. Neurol. 137, 242-254

38. Hamm, R. J., Pike, B.R., O’Dell, D.M., Lyeth, B.G., and Jenkins, L.W. (1994). The rotarod test: an evaluation of its effectiveness in assessing motor deficits following traumatic brain injury. J. Neurotrauma 11, 187-196.

39. Jakeman, L.B. (2012). Assessment of lesion and tissue sparing volumes following spinal cord injury, in: Animal Models of Acute Neurological Injuries II. J. Chen, X.M. Xu, X., Z.C. Xu, and J.H. Zhang (eds). Humana Press Springer: New York: pps. 417-442.

40. Scheff, S. W., Saucier, D.A., and Cain, M.E. (2002). A statistical method for analyzing rating scale data: the BBB locomotor score. J. Neurotrauma 19, 1251-1260.

41. Ferguson, A. R., Hook, M.A., Garcia, G., Bresnahan, J.C., Beattie, M.S., and Grau, J.W. (2004). A simple post hoc transformation that improves the metric properties of the BBB scale for rats with moderate to severe spinal cord injury. J. Neurotrauma 21, 1601-1613.

42. Barros Filho, T. E. and Molina, A.E. (2008). Analysis of the sensitivity and reproducibility of the Basso, Beattie, Bresnahan (BBB) scale in Wistar rats. Clinics. (Sao Paulo) 63, 103-108.

43. Ferrero, S. L., Brady, T.D., Dugan, V.P., Armstrong, J.E., Hubscher, C.H., and Johnson, R.D. (2014). Effects of lateral funiculus sparing, spinal lesion level, and gender on recovery of bladder voiding reflexes and hematuria in rats. J. Neurotrauma 32, 200-208.

44. Anderson, K. D., Sharp, K.G., and Steward, O. (2009). Bilateral cervical contusion spinal cord injury in rats. Exp. Neurol. 220, 9-22.

45. Primeaux, S. D., Tong, M., and Holmes, G.M. (2007). Effects of chronic spinal cord injury on body weight and body composition in rats fed a standard chow diet. Am. J. Physiol. Regul. Integr. Comp. Physiol. 293, R1102-R1109.

46. Steward, O., Popovich, P.G., Dietrich, W.D., and Kleitman, N. (2012). Replication and reproducibility in spinal cord injury research. Exp. Neurol. 233, 597-605.

47. Popovich, P. G., Tovar, C.A., Wei, P., Fisher, L., Jakeman, L.B., and Basso, D.M. (2012). A reassessment of a classic neuroprotective combination therapy for spinal cord injured rats: LPS/pregnenolone/ indomethacin. Exp. Neurol. 233, 677-685.

48. Simard, J. M. and Gerzanich, V. (2012). When replication teaches more than the original experiment-the saga of the unknown unknown. Exp. Neurol. 233, 623-624.

49. You, S. W., Chen, B.Y., Liu, H.L., Lang, B., Xia, J.L., Jiao, X.Y., and Ju, G. (2003). Spontaneous recovery of locomotion induced by remaining fibers after spinal cord transection in adult rats. Restor. Neurol. Neurosci. 21, 39-45.
50. Kloos, A. D., Fisher, L.C., Detloff, M.R., Hassenzahl, D.L., and Basso, D.M. (2005). Stepwise motor and all-or-none sensory recovery is associated with nonlinear sparing after incremental spinal cord injury in rats. Exp. Neurol. 191, 251-265.

51. Fouad, K., Hurd, C., and Magnuson, D.S. (2013). Functional testing in animal models of spinal cord injury: not as straight forward as one would think. Front. Integr. Neurosci. 7, 85.

52. Irvine, K. A., Ferguson, A.R., Mitchell, K.D., Beattie, S.B., Lin, A., Stuck, E.D., Huie, J.R., Nielson, J.L., Talbott, J.F., Inoue, T., Beattie, M.S., and Bresnahan, J.C. (2014). The Irvine, Beatties, and Bresnahan (IBB) Forelimb Recovery Scale: an assessment of reliability and Validity. Front. Neurol. 5, 116

53. Schrimsher, G. W. and Reier, P.J. (1993). Forelimb motor performance following dorsal column, dorsolateral funiculi, or ventrolateral funiculi lesions of the cervical spinal cord in the rat. Exp. Neurol. 120, 264-276.

54. Soblosky, J. S., Song, J.H., and Dinh, D.H. (2001). Graded unilateral cervical spinal cord injury in the rat: evaluation of forelimb recovery and histological effects. Behav. Brain Res. 119, 1-13.

55. Anderson, K. D., Sharp, K.G., Hofstadter, M., Irvine, K.A., Murray, M., and Steward, O. (2009). Forelimb locomotor assessment scale (FLAS): novel assessment of forelimb dysfunction after cervical spinal cord injury. Exp. Neurol. 220, 23-33.

56. Gensel, J. C., Tovar, C.A., Hamers, F.P., Deibert, R.J., Beattie, M.S., and Bresnahan, J.C. (2006). Behavioral and histological characterization of unilateral cervical spinal cord contusion injury in rats. J. Neurotrauma 23, 36-54.

57. Urbani, A. and Belluzzi, O. (2000). Riluzole inhibits the persistent sodium current in mammalian CNS neurons. Eur. J. Neurosci. 12, $3567-3574$.

58. Tazerart, S., Viemari, J.C., Darbon, P., Vinay, L., and Brocard, F. (2007). Contribution of persistent sodium current to locomotor pattern generation in neonatal rats. J. Neurophysiol. 98, 613-628.

59. Lamanauskas, N. and Nistri, A. (2008). Riluzole blocks persistent Na+ and $\mathrm{Ca} 2+$ currents and modulates release of glutamate via presynaptic NMDA receptors on neonatal rat hypoglossal motoneurons in vitro. Eur. J. Neurosci. 27, 2501-2514.

60. Lamas, J. A., Romero, M., Reboreda, A., Sanchez, E., and Ribeiro, S.J. (2009). A riluzole- and valproate-sensitive persistent sodium current contributes to the resting membrane potential and increases the excitability of sympathetic neurones. Pflugers Arch. 458, 589-599.

61. Xie, R. G., Zheng, D.W., Xing, J.L., Zhang, X.J., Song, Y., Xie, Y.B., Kuang, F., Dong, H., You, S.W., Xu, H., and Hu, S.J. (2011). Blockade of persistent sodium currents contributes to the riluzoleinduced inhibition of spontaneous activity and oscillations in injured DRG neurons. PLoS. One. 6, e18681.

62. Simard, J. M., Yurovsky, V., Tsymbalyuk, N., Melnichenko, L., Ivanova, S., and Gerzanich, V. (2009). Protective effect of delayed treatment with low-dose glibenclamide in three models of ischemic stroke. Stroke 40, 604-609.

63. Grossman, R. G., Fehlings, M.G., Frankowski, R.F., Burau, K.D., Chow, D.S., Tator, C., Teng, A., Toups, E.G., Harrop, J.S., Aarabi, B., Shaffrey, C.I., Johnson, M.M., Harkema, S.J., Boakye, M., Guest, J.D., and Wilson, J.R. (2014). A prospective, multicenter, phase I matched-comparison group trial of safety, pharmacokinetics, and preliminary efficacy of riluzole in patients with traumatic spinal cord injury. J. Neurotrauma 31, 239-255.

64. Levi, A. D., Casella, G., Green, B.A., Dietrich, W.D., Vanni, S., Jagid, J., and Wang, M.Y. (2010). Clinical outcomes using modest intravascular hypothermia after acute cervical spinal cord injury. Neurosurgery 66, 670-677.

65. Dididze, M., Green, B.A., Dietrich, W.D., Vanni, S., Wang, M.Y., and Levi, A.D. (2013). Systemic hypothermia in acute cervical spinal cord injury: a case-controlled study. Spinal Cord 51, 395-400.

66. Sheth, K. N., Kimberly, W.T., Elm, J.J., Kent, T.A., Mandava, P., Yoo, A.J., Thomalla, G., Campbell, B., Donnan, G.A., Davis, S.M., Albers, G.W., Jacobson, S., Simard, J.M., and Stern, B.J. (2014). Pilot study of intravenous glyburide in patients with a large ischemic stroke. Stroke 45, 281-283.

67. Dionyssiotis, Y. (2012). Malnutrition in spinal cord injury: more than nutritional deficiency. J. Clin. Med. Res. 4, 227-236.

68. Chen, X., Liu, Z., Sun, T., Ren, J., and Wang, X. (2014). Relationship between nutritional status and mortality during the first 2 weeks following treatment for cervical spinal cord injury. J. Spinal Cord Med. $37,72-78$. 
69. Shao, J., Zhu, W., Chen, X., Jia, L., Song, D., Zhou, X., Yan, W., and Zhang, Y. (2011). Factors associated with early mortality after cervical spinal cord injury. J. Spinal Cord Med. 34, 555562.

70. Gorgey, A. S., Dolbow, D.R., Dolbow, J.D., Khalil, R.K., Castillo, C., and Gater, D.R. (2014). Effects of spinal cord injury on body composition and metabolic profile-part I. J. Spinal Cord Med. 37, 693702.

71. Mayer, P., Haas, B., Celner, J., Enzmann, H., and Pfeifer, A. (2011). Glitazone-like action of glimepiride and glibenclamide in primary human adipocytes. Diabetes Obes. Metab. 13, 791-799.

72. Fukuen, S., Iwaki, M., Yasui, A., Makishima, M., Matsuda, M., and Shimomura, I. (2005). Sulfonylurea agents exhibit peroxisome proliferator-activated receptor gamma agonistic activity. J. Biol. Chem. 280, 23653-23659
73. Shi, H., Moustaid-Moussa, N., Wilkison, W.O., and Zemel, M.B (1999). Role of the sulfonylurea receptor in regulating human adipocyte metabolism. FASEB J. 13, 1833-1838.

74. Simmons, D. (2014). Safety considerations with pharmacological treatment of gestational diabetes mellitus. Drug Saf. 38, 65-78.

Address correspondence to:

J. Marc Simard, MD, PhD

Departments of Neurosurgery, Pathology, and Physiology

University of Maryland

22 S. Greene Street, Suite S12D

Baltimore, MD 21201-1595

E-mail: msimard@smail.umaryland.edu 